\title{
UPAYA PENANGGULANGAN SAMPAH ORGANIK DI DESA MAOS LOR CILACAP MENGGUNAKAN KOMPOSTER AYUN
}

\author{
Nurlinda Ayu Triwuri*1, Rosita Dwityaningsih ${ }^{2}$, Oto Prasadi ${ }^{3}$, Eka Dyah Puspita Sari ${ }^{4}$ \\ Teknik Pengendalian Pencemaran Lingkungan, Politeknik Negeri Cilacap ${ }^{1,2}$ \\ Teknik Mesin Perikanan, Politeknik Negeri Cilacap ${ }^{3}$ \\ Teknik Informatika, Politeknik Negeri Cilacap ${ }^{4}$ \\ e-mail : ${ }^{* 1}$ nurlindaayutriwuri@gmail.com, ${ }^{2}$ rosita.dwityaningsih2@gmail.com, \\ 30to.prasadi@gmail.com, ${ }^{4}$ ekadyah.puspitasari@yahoo.com
}

\begin{tabular}{l|l} 
Informasi Artikel & Abstract \\
\hline $\begin{array}{l}\text { Diterima Redaksi: } \\
\text { Revisi Akhir: }\end{array}$ & $\begin{array}{l}\text { Population growth and settlements have significant consequences on basic } \\
\text { problems. One of the main problems that arises and needs to be planned is } \\
\text { waste problem. Large amount of unhandling landfill causes various } \\
\text { problems, both directly and indirectly for the city population, especially } \\
\text { the community members in Desa Maos Lor, Dusun Tengah RW 11 who } \\
\text { own a Waste Bank. The problem from Waste Bank is the organic waste } \\
\text { that is not utilized and managed optimally, instead it is allowed to } \\
\text { accumulate and rot, so it pollutes the environment. The potential method } \\
\text { Organic waste, Swing composter, Solid } \\
\text { organic fertilizer, Liquid organic } \\
\text { fertilizer. }\end{array}$ \\
$\begin{array}{l}\text { Korespondensi } \\
\text { No. HP: }\end{array}$ & $\begin{array}{l}\text { to produce fertilizer or compost, which is a swing composter. The } \\
\text { composition in the swing composter consists of husk as the base, compost } \\
\text { as the starter, fine organic waste (in the form of residual waste or kitchen } \\
\text { waste), then it is covered with husk. To speed up the occurrence of decay, } \\
\text { the kitchen waste is chopped into small size. Then, the composter is swung } \\
5 \text { to } 10 \text { times for mixing it with microorganisms. Next step is letting the } \\
\text { swing composter for 4 months. Liquid organic fertilizer and solid organic } \\
\text { fertilizer can be used by residents of Desa Maos Lor Dusun Tengah RW } \\
11 \text { to grow crops. }\end{array}$
\end{tabular}

\section{Pendahuluan}

Pertumbuhan penduduk dan permukiman di dalam suatu wilayah kota, memberikan konsekuensi permasalahan yang cukup mendasar. Salah satu diantara masalah utama yang muncul dan perlu penanganan secara terencana adalah masalah sampah (Triwuri,N.A, 2014). Sampah yang dibuang oleh masyarakat setiap harinya berasal dari kegiatan pertanian, pasar, rumah tangga, hiburan dan industri. Salah satu bentuk sampah adalah sampah domestik yang merupakan salah satu kegiatan rumah tangga yang menyisakan limbah domestik atau sampah masyarakat. Bertambahnya sampah domestik sejalan dengan perkembangan pembangunan fisik, dan pertambahan peningkatan sarana dan prasarana yang memadai. (Mulasari,S.A dan Sulistyawati, 2014).

Limbah domestik merupakan limbah yang dihasilkan paling banyak tiap hari oleh berbagai aktivitas rumah tangga, oleh karena itu permasalahan ini tidak dapat diabaikan. Limbah domestik memerlukan penanganan serius. Mikroorgnisme secara alami mampu mendegradasi bahan-bahan organik yang ada pada limbah domestik sehingga dapat meningkatkan kualitas limbah domestik. (Romayanto, M.E.W, et al, 2006).

Besarnya timbunan sampah yang tidak dapat ditangani tersebut akan menyebabkan 
berbagai permasalahan baik langsung maupun tidak langsung bagi penduduk kota. Dampak langsung dari penanganan sampah yang kurang bijaksana diantaranya adalah berbagai penyakit menular maupun penyakit kulit serta gangguan pernafasan, sedangkan dampak tidak langsungnya diantaranya adalah bahaya banjir yang disebabkan oleh terhambatnya arus air di sungai karena terhalang timbunan sampah yang dibuang ke sungai. (Nahadi, 2017).

Kebiasaan membuang sampah sembarangan dilakukan hampir di semua kalangan masyarakat tidak hanya warga miskin, bahkan mereka yang berpendidikan tinggi juga melakukannya. Ini sangat menyedihkan karena minimnya pengetahuan tentang sampah dan dampaknya. Perilaku buruk ini semakin menjadi karena minimnya sarana kebersihan yang mudah dijangkau oleh masyarakat di tempat umum (Mulasari,S.A dan Sulistyawati, 2014).

Dampak dari pembuangan sampah yang tidak mengindahkan ketentuan dapat menyebabkan terhambatnya penciptaan lingkungan yang baik dan sehat. Sampah yang menumpuk banyak dan beserakan dan bau yang menyengat hidung setiap orang yang lewat merupakan masalah yang harus segera ditangani. Sampah memberikan dampak negatif bagi pariwisata. Wisatawan menginginkan daerah yang dikunjungi dalam kondisi bersih, indah, nyaman dan aman (Mulasari,S.A dan Sulistyawati, 2014).

Sampah dibedakan menjadi 3 jenis yaitu organik, anorganik, dan khusus. Sampah organik berasal dari bahan - bahan penyusun tumbuhan dan hewan yang diambil dari alam atau dari kegiatan pertanian, perikanan, kegiatan rumah tangga, industri atau kegiatan lainnya (sampah dapur, sisa sayuran, kulit buah, buah busuk, kertas, daundaunan, jerami dan sekam). Sampah organik sayur-sayuran dan buah-buahan seperti layaknya kotoran ternak adalah substrat terbaik untuk menghasilkan biogas (Abidin.Z, et al, 2012).

Salah satu tantangan yang dihadapi oleh pengelola sampah khususnya di Dusun Tengah, Kabupaten Cilacap, Kecamatan Maoslor dan tim pengabdian, adalah penanganan masalah persampahan. Dimana tiap orang dalam kegiatan keseharihariannya membuang sampah kurang lebih 0,25/L/hari, bayangkan berapa banyaknya volume timbulan sampah jika jumlah penduduk di Desa Maoslor sekitar 7.893 jiwa, maka akan menghasilkan volume timbulan sampah organik dan anorganik sebanyak kurang lebih 1973,25/L/hari (Data BPPD Kab.Cilacap, 2016).

Di Desa Maoslor tepatnya di Dusun Tengah dalam setiap bulannya mengambil sampah dari beberapa tempat sekitarannya sebanyak kurang lebih ada 4 (empat) drum truk sampah. Untuk sampah anorganik masyarakat Dusun Tengah sudah melakukan pengelolaan sampah dengan memisahkan dan mengumpulkan plastik, botol-botol plastik, dan lain sebagainya. Sedangkan sampah organik (kotoran ternak, sampah dapur dan lain sebagainya) tidak banyak dimanfaatkan dan dikelola secara maksimal, tetapi dibiarkan menumpuk dan membusuk, sehingga dapat mengganggu pemandangan dan mencemari lingkungan. Salah satu cara penanggulangan sampah organik yang potensial untuk dikembangkan di Indonesia adalah dengan menerapkan teknologi komposter anaerobik untuk menghasilkan pupuk/kompos.

Salah bentuk investasi yang akan ditawarkan kepada masyarakat Dusun Tengah khususnya pengola sampah yaitu berupa edukasi pada program pengabdian ini maka tim pengabdi memberikan pengarahan kepada masyarakat sebagai media sarana informasi tentang sampah 
organik dan anorganik serta cara pemisahan sampah. Hal ini dimaksudkan, agar masyarakat lebih mudah untuk mengolah dan memanfaatkan sampah tersebut menjadi sampah yang bermanfaat bagi lingkungan sekitar.

Adapun investasi bagi masyarakat khususnya di Desa Maoslor Dusun Tengah, dari pengabdian ini adalah memanfaatkan sampah dapur, kotoran ternak dll agar dapat digunakan sebagai bahan baku untuk pembuatan pupuk kompos dan sebagai bahan campuran pupuk pabrikan. Alat komposter sebagai tempat olahan untuk pembuatan pupuk kompos.

Desa Maoslor merupakan desa pertanian dengan penghasil padi yang unggul dan budidaya perikanan dengan hasil utama ikan gurameh. Desa Maoslor terdapat ada 4 (empat) dusun yaitu Dusun Buaran, Dusun Lancar, Dusun Tengah dan Dusun Paningdian. Dari keempat dusun tersebut masih terbagi lagi menjadi 44 RT dan 15 RW. Jumlah warga Desa Maoslor sebanyak kurang lebih 4400an jiwa. Berdasarkan data tersebut maka pengelola sampah anorganik di Dusun Tengah sangat berperan sebagai mitra pertama pembuat pupuk kompos berbahan baku sampah organik (kotoran ternak, sampah dapur), sedangkan mitra keduanya adalah para petani dan ibu-ibu rumah tangga yang senang bercocok tanam di Desa Maoslor dan sekitarnya.

\section{Metode}

Dalam program pengabdian ini, metode yang akan dibuatkan alat utama dan alat penunjang. Alat utama berupa komposter ayun dan alat penunjang berupa mesin pencacah serta akan dilakukan pendampingan operasional sampai dihasilkan produk pupuk organik yang bisa digunakan oleh mitra kedua untuk kebun rumah tangga. Adapun susunan didalam komposter ayun yang menjadi dasarnya sekam, kompos jadi sebagai stater, sampah organik halus (berupa sisa limbah dapur), kemudian bagian atas ditutup dengan sekam. Di daerah Desa Maoslor Dusun Tengah banyak limbah jerami dan sekam maka bisa menjadi bahan tambahan untuk mengisi komposter.

Adapun gambar alat komposter yang sudah jadi sebagai berikut :

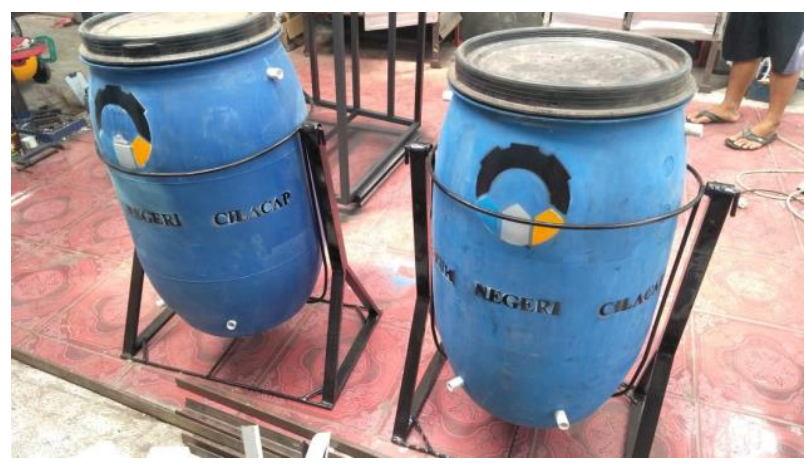

\section{Gambar 3.1. Tampak Depan Alat} Komposter

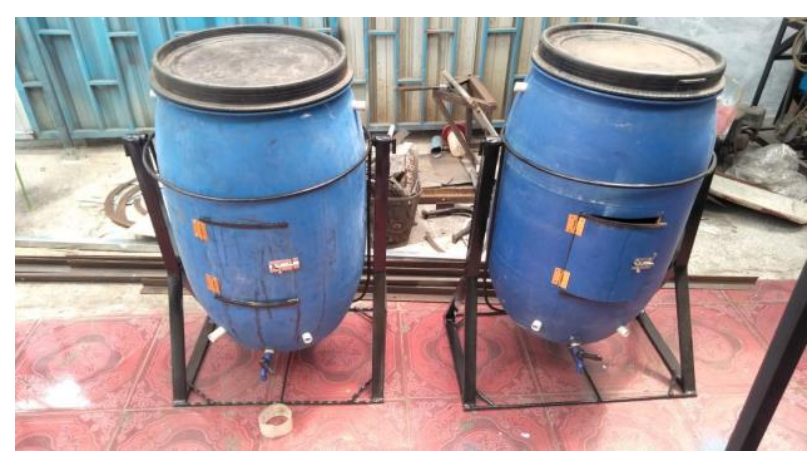

Gambar 3.2. Tampak Belakang Alat Komposter 


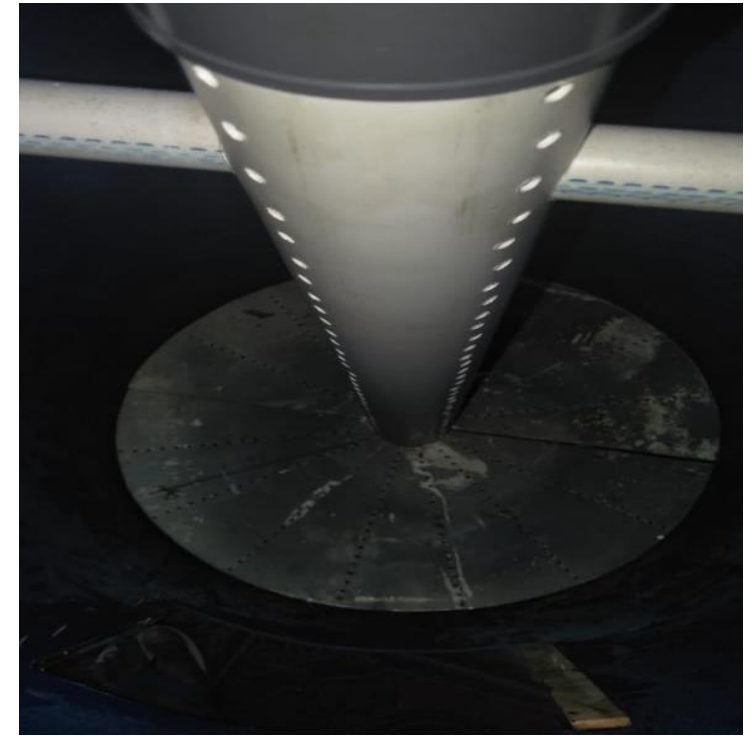

Gambar 3.3. Bagian dalam komposter ayun

\section{Cara Pengoperasian Alat komposter :}

1. Masukkan kompos, pupuk kandang atau sekam padi sebagai stater.

2. Masukkan sampah dapur ke dalam komposter putar dan ditutup.

3. Ayun komposter sebanyak 5-10 kali untuk pencampuran dengan mikroorganisme.

4. Air sampah terfermentasi (pupuk organik cair) yang tertampung dapat digunakan sebagai pupuk tanaman.

5. Diamkan komposter ayun yang sudah penuh selama 4 bulan.

6. Keluarkan kompos dari jendela bagian bawah komposter dan diangin-anginkan.

7. Pupuk organik padat (kompos) sudah dapat digunakan.

\section{Hasil dan Pembahasan}

Hasil kegiatan pengabdian kepada masyarakat adalah membuat kompos dari sampah organik bersama warga Desa Dusun Tengah RW 11 dengan menggunakan komposter ayun dan mesin pencacah untuk memperkecil sampah organik (batang sayur mayur, jerami padi, dan lain sebagainya).

Tim pengabdi melaksanakan kegiatan pengabdian kepada masyarakat di Bank
Sampah Dusun Tengah RW 11. Kegiatan ini bermaksud, memberikan solusi kepada pengelola Bank Sampah Dusun Tengah RW 11 Desa Maoslor untuk membantu mengurangi sampah organik yang belum teratasi dengan baik yaitu dengan pelatihan membuat kompos berikut dengan alat komposter dan mesin pencacah. Mesin pencacah sampah diperlukan untuk mencacah sampah organik menjadi berukuran kecil sehingga, untuk proses penguraian sampah organik semakin cepat membentuk produk pupuk kompos.

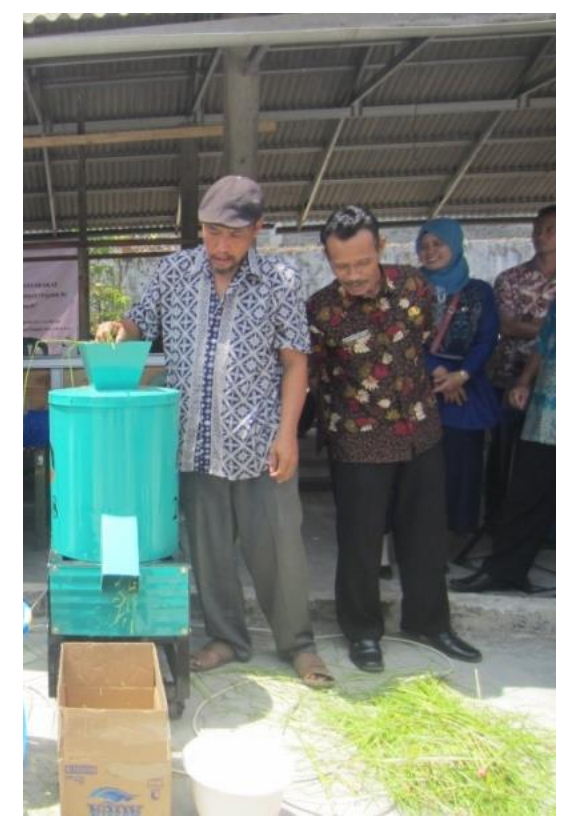

Gambar 3.4. Mesin Pencacah

Pembuatan kompos dengan media komposter ayun ini, sangat berguna bagi pengelola Bank Sampah untuk mengantisipasi sampah organik yang mudah membusuk dengan kapasitas yang cukup besar. Dalam hal ini, tim pengabdi menggunakan 2 buah komposter ayun yang masing - masing berkapasitas 120 liter sebagai media bagi tim pengabdi dalam mempraktekkan pembuatan kompos dengan harapan bisa mengurangi sampah organik dan memperoleh pupuk kompos dari sampah organik tersebut. Kelebihan pupuk kompos 
yang dihasilkan dari komposter ayun ini bisa menghasilkan 2 produk yaitu pupuk organik padat (POP) dan pupuk organik cair (POC). Kelemahan dari komposter ayun ini jika komposter ayun sudah penuh maka akan semakin berat untuk diayun. Hal ini disebabkan, karena komposter ayun dioperasikan dengan cara manual menggunakan tangan untuk mendorong komposter ayun agar komposisi terutama pupuk organik cair dibawahnya dapat tercampur ke atas dan meresap ke pupuk organik padat kemudian tertiriskan kembali menjadi pupuk organik cair.

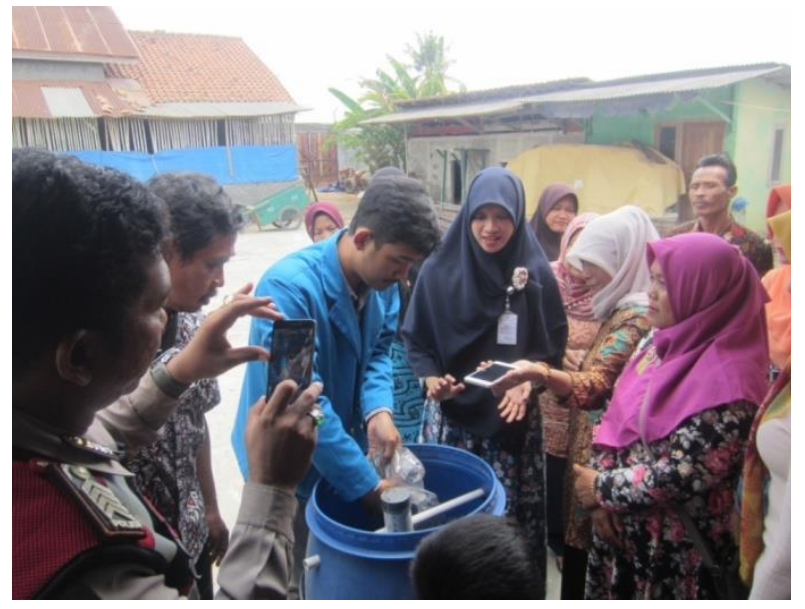

\section{Gambar 3.5. Penjelasan Membuat Kompos dengan Komposter Ayun}

\section{Kesimpulan}

Komposter ayun sebagai tempat untuk menguraikan sampah organik dengan jumlah yang cukup banyak. Pupuk organik atau kompos yang dapat dihasilkan dari komposter ayun ini ada 2 jenis yaitu pupuk organik padat (POP) dan pupuk organik cair (POC). Namun, komposter ayun ini juga mempunyai kelemahan yaitu jika kapasitasnya sudah terlalu penuh, maka komposter ayun akan semakin berat pula untuk diayun. Pupuk kompos hasil dari komposter ayun juga membutuhkan selang waktu yang cukup lama sekitar kurang lebih 4 bulan, sehingga memerlukan komposter ayun yang banyak pula.

\section{Ucapan Terima Kasih}

Program Pengabdian Kepada Masyarakat ini Didanai oleh DIPA Politeknik Negeri Cilacap melalui Hibah Bersaing Internal Tahun 2018

\section{Daftar Pustaka}

Abidin.Z, Handayani,D, Afriyani,I, dan Silvianita,D, 2012, "Pengembangan Proses Degradasi Sampah Organik Untuk Produksi Biogas dan Pupuk", Seminar Nasional Kimia dan Pendidikan Kimia IV, Program Studi Pendidikan Kimia Jurusan PMIPA FKIP UNS, Surakarta. Fakultas Teknik, Universitas Diponegoro.

Badan Perencanaan Pembangunan Daerah (BPPD) Kabupaten Cilacap, Data Dasar Kecamatan Maos, 2016.

Nahadi, 2017, "Program Pengelolaan Sampah Melalui Pemanfaatan Teknologi Komposting Berbasis Msyarakat", Jurusan Pendidikan Kimia FPMIPA UPI.

Mulasari, S.A dan Sulistyawati, "Keberadaan TPS Legal dan TPS Ilegal Di Kecamatan Godean Kabupaten Sleman", Jurnal Kesehatan Masyarakat KEMAS 9 (2) (2014) 122-130 Fakultas Kesehatan Masyarakat, Universitas Ahmad Dahlan, http://journal.unnes.ac.id/nju/index.php/ke mas.

Romayanto,M.E.W， Sajidan,W., 2006, “ Pengolahan Limbah Domestik dengan Aerasi dan Penambahan Bakteri Pseudomonas putida", Jurnal Bioteknologi 3 (2): 42-49, Nopember 2006, ISSN : 0216-6887, Jurusan Biologi FMIPA Universitas Sebelas Maret, Surakarta. 
Triwuri,N.A, "Model Estimasi Volume Timbulan Sampah Terhadap Peningkatan Jumlah Penduduk", Jurnal Rekayasa Sistem Industri Vol. 1, No.1, November 2015 ISSN : 2477-2089. 